\title{
OMB announces cap
}

\section{Washington}

THE White House Office and Management and Budget (OMB) has revealed the details of its proposed cap on the rates that US universities can charge to federal grant-making agencies to cover the overhead, or "indirect", costs of research. As expected, the new rules would limit the portion of overhead charged to cover universities' administrative costs to 26 per cent of the value of research grants - about the average current rate.

The 26 per cent cap comes into force for any overhead contracts negotiated or amended after 30 September, and is expected to cost US universities at least $\$ 75$ million over the coming year.

Robert Rosenzweig, executive director of the Association of American Universities, is concerned about this compressed timescale. "There's a case to be made for phasing the cap in for institutions that are going to be hit hard in the short term," he says. For universities that now receive high rates of administrative overhead, those rates may have been won in the give-and-take of negotiations at the expense of a lower reimbursement for the costs of buildings and equipment. Capping the administrative overhead without modifying the other parts of the contracts could be unfair to the schools.

Universities have until the end of July to comment on the proposed rules. Given the current scandal over indirect costs, few observers expect major changes in response to university protest.

Michael Hall, a staff member at the Senate appropriations subcommittee responsible for the National Institutes of Health's budget, says that any controls coming from Congress would probably be even stricter.

Rosenzweig concedes that, for the time being, the universities will have to live with a 26 per cent cap on administrative costs.

But he wants federal agencies to agree quickly on a new system of accounting for and reimbursing research overheads, so that the cap does not become a permanent fixture. Rosenzweig's association had been negotiating with the $\mathrm{OMB}$ to reform the system, before congressional outrage earlier this year at the inclusion of a yacht and other luxuries in university research accounts at Stanford University forced more drastic action by the $\mathrm{OMB}$.

\section{Superconductivity hot again}

\section{Washington}

ADVANCES in high-temperature superconductivity have ben so rapid over the past year that the use of superconductors in electric power systems, large motors and other energy applications is likely to come much sooner than most expected.

For that reason, the United States should form a $\$ 250$-million, five-year programme to develop electric energy systems that use high-temperature superconductors. So says a report issued late last month by a group of superconductivity specialists from industry, academia and national laboratories.

"The progress has been astonishing," says Alex Malozemoff, vice president of research and development at American Superconductor Corporation in Watertown, Massachusetts, and a member of the group that wrote the report. "In the last year it has been confirmed that one can actually build things with these materials."

After the initial euphoria accompanying the discovery of high-temperature superconductors died down, researchers found several problems with the materials that threatened to slow the development of 'bulk' applications - such as wires, magnets and motors - to a crawl. The superconductors were brittle and inflexible, which made them poor candidates for wires that would be wound in coils, and they exhibited a variety of interrelated problems that limited their critical current density - the amount of current they could carry and still remain super-

\section{conducting.}

But the progress in increasing the critical current density has been faster than anyone expected, and American Superconductor and other labs have shown they can make flexible superconducting wire. Suddenly, people are again excited over the potential applications of high-temperature superconductors to such devices as magnets, motors, generators and electrical transmission wires.

That creates an opportunity for US industry, the report says.

Japanese and European researchers are developing superconducting power systems that use the traditional low-temperature superconductors. "With an aggressive program, the United States could leapfrog its competition by demonstrating the components of a high-temperature system within the next five years," the report predicts. One of the most valuable applications would be superconducting motors, it says.

The five-year programme envisioned in the report would be led by the federal government but with significant private-sector investment. For each class of applications, the report recommends establishing "vertically integrated, industry-led teams with representation from manufacturing, universities, national laboratories" and end users of high-temperature superconductor such as electric utilities. The development would take place at "a pre-competitive level but with a long-term, market-driven focus."

Robert Pool
State universities are particularly concerned about a second provision in the OMB's proposals demanding that money reimbursed for depreciation of buildings and equipment is actually used to cover future building and equipment costs. University officials liken this to an employee submitting an expenses form for a business lunch, and then being forced to spend the reimbursement on another lunch. The lack of budgetary flexibility, says Bill Brophy, a finance officer responsible for indirect costs at the University of California, San Diego, will make it more difficult for state universities to return money owed to their state legislatures.

Peter Aldhous

n In a separate development last week, the Office of Naval Research announced that it has disciplined six of its civilian employees, responsible for negotiating the indirect cost rate on research grants to Stanford University.

The action against the six civilians ranges from assignment to another job and a cut in pay, to a simple letter of admonishment.

The Navy's move is the first action taken against federal officials who failed to prevent the charging of luxury items to university research accounts. Stanford alone has now returned over \$1 million incorrectly charged to research overhead - a minute fraction of the total sum thought to be charged incorrectly by Stanford to the US taxpayer over the 1980 s.

\section{TECHNOLOGICAL RESEARCH - \\ US losing its lead}

\section{Washington}

THE United States' world lead in technological research is diminishing, according to an analysis of the Institute for Scientific Information's Science Indicators database, published in the latest issue of Science Watch. The average citation impact of papers with US authors in most fields rose through the $1980 \mathrm{~s}$. But in engineering, technology and applied sciences, those research areas most closely linked to industrial competitiveness, the citation of US papers has fallen by 6.9 per cent, relative to the world average. The sharpest decline was in metallurgy $\mathbf{- 2 0 . 3}$ per cent, nuclear engineering $\mathbf{- 1 8 . 1}$ per cent, and instrumentation -13.6 per cent.

Somewhat surprisingly, the declining impact of US technological research papers is not due to a corresponding rise in citations of papers from Japan, whose technologists are no more likely to be cited now than in the early 1980s. Instead, it seems that it is France and Britain that are the growing forces in engineering, technology and applied science. But US technologists should not panic.

Despite the decline in citation impact over the 1980 s, US technological research papers are still cited over 60 per cent more often than the average for those from the $\mathrm{G} 7$ group of nations. 